\title{
COST-BENEFIT ANALYSIS: TOO OFTEN BIASED
}

\author{
Eliška Vejchodská
}

\section{Introduction}

In current political practice in many countries, cost-benefit analysis (CBA) is applied in evaluating public projects and regulatory instruments. In evaluation using CBA, the effort is to express the comprehensive effect of a project or a governmental regulation on social welfare. Social welfare can be affected by changing environmental quality, improving quality of life due to better healthcare, etc. Since many projects essentially affect environmental quality either positively or adversely, the effect of non-monetary costs and benefits derived from changing environmental quality is often involved in CBA in addition to financial costs and benefits. CBA is therefore an evaluation method widely discussed in neoclassical environmental economics, e.g. [13], [12].

What has enabled CBA to become one of the most widespread methods in political decisionmaking? Dryzek [6] offers an explanation in his environmental discoursive analysis. According to him, methods such as CBA, risk analysis and EIA (environmental impact assessment) have penetrated political practice due to the overwhelming conviction that decision-making on political issues should be left to experts. That is why he believes expert agencies such as the US EPA (Environmental Protection Agency) and the United Nations Environment Programme have come into existence. CBA introduces this expertise to political decision-making. From the point of view of neoclassical economics, CBA is capable of answering the question whether a policy project or regulatory tool is beneficial or detrimental to society. According to neoclassical environmental economics, therefore, politicians should subject their crucial decisions influencing environmental quality to CBA. CBA advocates also see its application as a way to improve the efficiency of control over the meaningfulness of political action, increase the transparency of regulation and diminish the influence of lobby groups, as discussed e.g. in [4]. Politicians' decisions are not random: political action is supported by CBA results [1].

In the USA since Reagan's era the requirement to decide based on $\mathrm{CBA}$ in regulatory impact analyses (RIA) was anchored in the legislation by Executive Order 12291 in 1981. All the governmental agencies, including EPA, employ CBA in their decision-making [1]. The basic requirement for a monetary expression of monetarily quantifiable effects, therefore the application of CBA in RIA, remains preserved till now in the USA (partial amendments by Clinton's Executive Order 12866 in 1993 and Obama's Executive Order 13536 in 2011). CBA is also in abundant use in the EU political decision-making, although RIA analyses across European countries vary in their methodologies used for impact assessment. The only country long insisting on CBA for RIA analyses has been the UK [23]. In major European countries including France, Germany, Spain or Italy, RIA does not contain a robust economic appraisal [5]. CBA has been largely used in EU countries as a basis for decisions concerning allocation of subsidies from Structural Funds and the Cohesion Fund.

Although neoclassical economists agree on the meaningfulness of using CBA in decisionmaking, they subject parts of its methodology to scholarly reflection. CBA as a method within neoclassical economics has therefore been evolving in some aspects. Its real-world applications make use of different procedures based on different arguments. Due to the disunited methodology employed in practical CBA execution, the results of studies may be misleading. Two different studies of the same thing based on different methodologies may arrive at fundamentally different conclusions. CBA results may also be deliberately distorted 
by adjusting the method chosen to the required outcome. However, practical CBA may also involve other problems such as the degree of expertise of its performers (methodological problems of CBA for the Dutch case discussed in [20]).

This paper outlines the methodological disagreements in the performance of CBA. It further focuses on issues of practical CBA applications from the point of view of impartiality of CBA performers. We bring a criticism of the current setting of CBA execution. As an example, we use CBA performed for the purposes of applying for EU funding from Structural Funds in the Czech Republic. Our theoretical analysis shows that with the current setting of rules for the CBA performance for the purposes of EU funding, its performers cannot be expected to show expertise and impartiality. We support the theoretical analysis results with data from our own empirical survey among commercial CBA performers who offer consulting in the area of EU Structural Funds. There is no reason to believe that the Czech Republic is a mere exception in this sense and that CBA performance works any better in other countries.

The first section of the paper outlines the theoretical basis of CBA grounded in neoclassical economics. The next section presents critical arguments voiced from the neoclassical economic school. This discussion is followed by a section dealing with the issues of practical CBA application on the example of the Czech Republic. The final section of the paper presents suggestions for resolving the current unsatisfactory situation.

\section{Theoretical Grounding of CBA}

CBA is based in neoclassical economics, currently the mainstream of economic theory. Since CBA is widely applied in environmental protection, we shall make the introduction to its theoretical grounding using environmental CBA as an example. The introduction to neoclassical environmental economics may be found e.g. in [26]. CBA rests upon an anthropocentric valuation of the environment, that is, the humans' subjective valuation based on their individual preferences. Neoclassical economics is based on consumer sovereignty, sees consumer preferences as exogenous and respects any subjective consumer opinion. The question an economist solves is the optimum allocation of resources based on these preferences [12]. In CBA, these preferences are then reflected in the monetary valuation of environmental goods and services as well as other nontraded goods. The value of environmental goods and services expresses an individual's willingness to pay for an improvement or a change to the quantity of the environmental goods and services, or willingness to accept monetary compensation for deterioration of the environmental goods and services. The total social value of a certain natural resource is then the sum of the subjective individual values attributed to it by the individuals within the society [16]. Environmental economics has developed a number of special methods in order to seek for environmental value (for more on environmental valuation methods, see, e.g. [9], [13], [30], [19]).

The purpose of CBA is to decide on the worthiness of a public investment or regulation (e.g. investment in a wastewater treatment plant) based on quantitatively expressed benefits and costs. Thus it seeks to bring the nature of the public sector decisionmaking closer to the situation common in the private sector. A company will also weigh the costs and benefits of its business plans. The recoverability of public funds is viewed in CBA in connection with balancing social benefits and costs. If a public investment brings no financial gains yet we maintain that it is socially beneficial, it has to bring other benefits than financial, such as environmental improvement and, through it, welfare increase of its users. When assessing the suitability of public plans from this point of view, a plan whose total benefits discounted to the present value outweigh its total discounted costs is justifiable. In the case of the wastewater treatment plant, CBA will balance the social benefits, which may be benefits derived from reduced watercourse pollution, against the social costs, which may be the capital investment and operating costs of the treatment plant and the adverse impact of the treatment plant on the local environment (odour near the plant, affecting the quality of housing, for example). The mainstream CBA methodology (not every CBA advocate identifies with the mainstream CBA method, as we will see below) is based on the KaldorHicks compensation criterion. This criterion tests the possibility of those who have benefited from the project compensating for those who 
have suffered a loss from it. According to this criterion, the public sector plan in question is welfare increasing if, after its execution, goods can theoretically be redistributed so that the situation after the redistribution of these goods is a Pareto improvement to the no-project situation [1].

It follows from the above that the result of CBA describes the effective demand for a public plan [13]. Not only does it show every person's voting on the matter but it can also discover the degree of their preference. The different voices for and against do not weigh the same in CBA. They are weighted according to the degree of preference, expressed here as the degree of willingness to pay or willingness to accept compensation.

\section{Methodological Disunities of CBA}

Although the CBA method is highly elaborated and widely recognised, there is no agreement in opinion among economists concerning its methodology. We shall focus on a discussion of the normative issues of equity, (re)distribution of wealth in society and mutual equality of people (discussion of other issues e.g. in [29], [7]). Gramlich [10] deals with the distribution issues connected with CBA in detail. He points out that two different projects - one bringing net benefit to the poor, the other bringing the same net benefit per dollar invested to the rich - are equal from the CBA point of view. According to the CBA result, it does not matter which of the projects is chosen. Still, the society may prefer a more desirable redistribution of wealth, normatively towards the poor. Mainstream CBA is nothing more and nothing less than a KaldorHicks compensation test. Since no actual compensations are made in reality (actual compensations are not technical feasible due to enormous transaction costs), the project may result in a shift of wealth from the poor towards the rich, thus exacerbating inequalities in society. Even a project that brings an additional effect to the wealthiest social class to which the entire society contributes may increase the social welfare according to CBA. CBA does not examine who suffers a loss from a project (the poor or the rich) and who earns from it.

Moreover, as stated by Hanley and Spash [13], the relatively richer have a relatively stronger vote in CBA than the relatively poorer. Their willingness to pay or accept compensation will be higher in absolute terms than those of the poor. The votes would weigh equally only under the condition of the equal distribution of wealth in society [13]. The CBA outcome is therefore dependent on the wealth distribution in society and will more likely unfold from the desires of the relatively richer social classes.

According to Adler and Posner [1], however, it is correct that CBA does not consider the distribution of wealth. They believe that economists dealing with economic efficiency and changes in total welfare have nothing to say on the wealth distribution in society. According to them, the wealth distribution in society is a purely political issue. If a government wishes to redistribute wealth, Adler and Posner [1, p. 186] consider that a more cost-effective way is "through taxes and transfers rather than by building dams in poor areas or toxic waste dumps in rich areas". Among others, also Frank [8] mentions tax progression as a solution to the problems of the poor. On the other hand, some economists see an opportunity to include equity issues directly in CBA by means of explicit distribution weights of votes. However, that would imply weighting individuals' willingness to pay based on the individuals' marginal utility of money. The discussion of distribution weight of votes is summed up in [1].

Sen [25] in his reflection of CBA focuses on methods for valuating public goods; defining them in accordance with Samuelson's approach as non-rival goods that cannot be excluded from consumption (for the summary of other Sen's comments to CBA, see [15]) . They are evaluated in the same way as if they were private goods: individuals' willingness to pay for the provision of these goods is sought just as if the individuals were capable of paying for the goods individually, without the help of others. Sen [25] quotes the Exxon Valdez disaster as an example. In ordinary contingent valuation, the researcher asks how much you would be willing to pay to restore the environment to the state prior to the disaster. Say your reply as a respondent's is 20 dollars. However, that is an irrelevant scenario according to Sen. One cannot pay 20 dollars and believe that the disaster consequences will be removed thanks to one's payment. The personal sacrifice of the payment to which contingent valuation is bound changes very little in providing the good; the payment itself changes virtually nothing in a disaster of the Exxon Valdez dimensions. Sen compares an individual's decision-making 
concerning the purchase of a private good to that concerning the individual's contribution to environmental protection. Whereas you are unaffected by other people's willingness to pay when buying a private good, such as a tube of toothpaste, you tend to be strongly influenced by whether and how much others are willing to pay when deciding about your contribution to environmental protection. Sen [25] highlights the need for a common effort to provide a public good. Instead of the usual valuation based on a market analogy, Sen believes the method should employ the social choice model, formulated by Arrow [3]. His idea is to confront respondents with realistic alternative solutions, including the explicit statement of possible responses by other members of society.

CBA advocates have been intensely discussing the discounting method and discount rate used in CBA, e.g in [2]. Exponential discounting, working with a constant discount rate, is the norm. As summarized in [8], exponential discounting does not match people's decision-making patterns. Hyperbolic discounting, in other words a gradual reduction in the discount rate over time, would be a closer representation. Faced by the decision to accept 100 dollars today or 105 dollars in a week versus 100 dollars in a year or 105 dollars in a year and a week, most people will choose 100 dollars today in the former case and 105 dollars in a year and a week in the latter. In the latter case, deciding about an event that will occur a year from now, the perceived time value of money does not decrease as fast over a week as in the former case. One prefers to wait for an extra week to get a larger amount of money. This should correspond to a decreasing discount rate over time. Assuming a constant discount factor, the decisions should be identical: either the person should choose 100 dollars in both cases or 105 dollars in both cases, depending on the individual's discount rate [8]. The height of the discount rate is another aspect thoroughly discussed among economists. It may vary considerably from a rate close to zero to $20 \%$. Also for these extreme discount rates a justification may be found as summarized in [22]. Some economists prefer to use a discount rate based on the opportunity cost of capital (higher rates of exponential discounting), some prefer to derive the discount rate from the pure rate of social time preference which discounts welfare of future generations (lower rates of exponential as well as hyperbolic discounting). A valuable overview of the discussion of different concepts of social discount rent may be found in [14].

There is a fairly wide range of opinions on the correct CBA procedure among its advocates. Some insist on the application of the classic mainstream CBA based on the KaldorHicks compensation criterion, exponential discounting, etc. Others tend towards the accurate application of a less commonly used CBA method, such as the use of hyperbolic discounting and distribution weights of votes. Yet others refuse mechanistic adoption of the CBA methodology from textbooks and call for a certain flexibility. As stated by Adler and Posner [1], who defend the need for flexibility in drafting CBA techniques for specific applications, practical executions of CBA have to provide room for deontological ethics, for instance. This means that CBA recommendations may in no case violate some ethical rules: theft must not be recommended even if its social benefits outweigh its costs. They also say that CBA analyses should always respect the specific distribution of wealth in a society.

The pliability of the CBA method is related to one of the fundamental questions of its application. The possibility of choosing the CBA method results in a situation in which one CBA performer proves the net social benefit of a measure while another disproves it. A famous recent example is the debate of the appropriateness of investing in prevention of global climate change. According to Stern [27], investing in preventive measures in climate change pays off very well to society. Nordhaus [21] refutes Stern's result. In his view, Stern's analysis only arrives at that conclusion due to its use of a very low discount rate which was in Stern's analysis derived from a very low pure rate of social time preference and a specific utility function.

\section{Questions Concerning Practical Application of CBA in a Czech Republic Example}

Currently, the Czech Republic sees a wide application of CBA although there is no legal obligation for governmental agencies to employ CBA in their decision-making. There has admittedly been an obligation for the supreme state administration bodies to apply RIA when deciding about the establishment and form of 
any generally binding legal regulation in the Czech Republic since 2007. The Czech legal system does not impose any obligation to use a specific qualitative or quantitative analysis, such as CBA, as part of RIA. The choice is therefore up to the RIA performer (Government Resolution no 922/2011 Coll.). A large number of CBA are currently made chiefly for the purposes of obtaining subsidies from EU Funds. Applicants have frequently been required to elaborate CBA under the EU Structural Fund programming period 2007-2013 (see subsidy conditions of operational programmes and regional operational programmes of the Czech Republic). For an applicant to obtain a subsidy from the EU Funds, the CBA has to prove positive net social benefits of his project. In many programmes (e.g. Regional Operational Programmes and Operational Programmes Transport), the requirement to provide CBA has been derived from the project cost amount. A CBA has to be performed if project costs exceed a certain amount, typically tens or hundreds of millions of CZK (roughly units or tens of millions of EURO), depending on the conditions of each operational programme.

We demonstrate the chain of players in the Czech model of CBA performance for obtaining subsidies from EU Funds by the following scheme:

CBA performer $\rightarrow$ subsidy applicant $\rightarrow$ $\rightarrow$ officials processing subsidies $\rightarrow$ the public

Subsidy applicants are responsible for providing CBA for their projects on their own They typically commission the CBA with commercial contractors offering such services. Subsidy applicants pay for the elaboration of CBA with their own funds. The CBA performer is therefore in a contractor-customer relationship with the applicant. The CBA client is a customer whose interest is to prove a positive net social benefit of the project in order to obtain the subsidy. It is in the interest of the contractor to accommodate the customer. The CBA performer can choose many ways how to do so. We showed methodological disunities which may affect the CBA result above. CBA results can be further affected, for example, by the method of predicting future benefits and costs, the choice of "significant" and "unimportant" benefits and costs, which either enter the CBA or not, or the definition of stakeholders [13].
CBA results are therefore relatively easy to manipulate. The opportunity for influencing CBA results is supported by the fact that few people understand its methodology. Reviewing the correctness of CBA procedures is thus made difficult.

In the Czech Republic, the CBA performer bears no liability for its potential incorrectness. Anyone may offer CBA performance. No licence whatsoever is required that could be suspended or revoked if deficiencies are found in elaborated CBA, as is the case with the driving licence if you fail to comply with set rules. This, however, leads to a concern about the impartiality and expert level of CBA performed for the purposes of applications for EU funding. For the officials deciding on the subsidy, as well as for the public, in whose interest is not to waste money on unjustified projects, it is theoretically possible to supervise CBA. However, the general knowledge of the CBA methodology is very weak. This can be inferred from the fact that CBA methodology is not included in the overwhelming majority of university economic curricula. In such a situation, conscious officials or conscious members of the public cannot be expected to perform an effective review. Moreover, taking into account the arguments of the public choice school, such as officials' action to their own benefit, rational ignorance of voters, or the disadvantage of the public as a specific interest group consisting in its low level of organisation, an effective review and the discovery of potential errors in real-world CBA cannot be expected.

\section{The Survey among Czech CBA Performers}

In order to confirm our hypothesis of the low level of expertise and impartiality in performing CBA for purposes of EU subsidy applications, we carried out a survey among CBA performers. We addressed six randomly chosen commercial corporations which offer consulting in the area of EU Structural Funds including CBA performance on the Czech market (according to expert judgement there are tens of such corporations there). The survey method chosen was a questionnaire with openended questions joined with a face-to-face interview. We questioned a representative from each of these corporations who takes part in performing CBA. The rate of response return was $100 \%$. We inquired about (i) the 
expert background of addressed corporations concerning CBA performance, (ii) the methods used in CBA by their corporation, and (iii) the rate of $\mathrm{CBA}$ performed by their corporation proving a welfare increase.

The answers to (i) uncovered that employees pursuing CBA are not necessarily economists and therefore did not usually get in contact with CBA until in their job. If they are economists, they also often got in contact with CBA in their job for the first time. To be able to elaborate CBA, CBA performers in these companies use EU or national guides to CBA, visit additional training courses or learn about CBA from their colleagues.

As can be inferred from the answers to (ii), none of the addressed companies used an exact and reliable scientific method of CBA performance as known to economic theory and as presented in economic textbooks, e.g. in [13]. As the responses of corporation representatives show, these corporations did not discuss the choice of benefits and costs entering CBA thoroughly. The choice of CBA inputs for appraisal was executed by the CBA performer without any support for his or her choice in academic sources. These chosen benefits and costs were subsequently assessed with the utilisation of following data sources: clients of these corporations at the first place, less frequently existing statistical data (mainly from Czech Statistical Office), and own expert judgements. None of the addressed respondent collected data on his own and used standard methods for benefits and costs valuation described in economic textbooks, e.g. in [9], such as contingent valuation, or the hedonic price method. A typical procedure of the data formation and data processing in CBA performed by corporations in our sample may be demonstrated on a case described by one of respondents. The case deals with the calculation of benefits thanks to a school building reconstruction. The assumption of the performer was as follows: the school building reconstruction leads to a better learning environment and therefore better employment opportunities of graduates due to better learning outcomes. Better employment opportunities further lead to higher wages of graduates. The increase of wages is one of the project benefits. The CBA performer stated that to evaluate this benefit, he took the data of the number of school graduates from his client, used statistical data about the average wage in the particular field of study, and performed an expert judgement about the increase of graduates' wages above the average due to the school reconstruction. Annual benefits equalled the sum of wage increases of graduates in a particular year. It is not clear however, if and to which degree a better school environment leads to higher education outcomes. The CBA performer did neither cite any study to prove his hypothesis, nor did he realise his own survey testing this hypothesis. This benefit may equal to zero and loses its validity. A similar situation in the approach to costs and benefits' appraisal occurred in other companies of our sample. The unavoidable consequence is the loss of information power of these CBA results.

The answers to the rate of CBA results proving a welfare increase (iii) ranged between $90 \%$ and $100 \%$. It shows a high rate of CBA proving a welfare increase by assessed projects. A bias in favour of the client can be demonstrated on the following statement of a respondent. He stated that the costs and benefits valuation is just manipulation with numbers to prove beneficial effects of projects for his customers.

It can be inferred from this survey that at least a certain non-negligible segment of the commercial CBA performers processes CBA in an insufficient quality. At the same time, our findings lead us to conclude that CBA are not performed impartially and are frequently purely formal. The validity of our survey results may be supported in a broader context by the conclusion of the UK National Audit Office survey (cited in [23]) which was based on the assessment of performed RIA. According to this survey, the economic quality of English RIA using the cost-benefit appraisal is poor due to the poor quantification of benefits as well as poor transparency of data sources. In this context, the overall situation in the widespread use of CBA seems unsatisfactory.

\section{Deliberations on a Solution}

The current way of applying CBA for the purposes of applying for EU funding often leads to mendacious, unreliable conclusions. In addition, a precisely performed CBA is costly and time consuming due to the need of expressing all the benefits and costs in monetary terms based on valuation methods discussed in economic textbooks, e.g. [9]. 
Therefore the application of less demanding alternative evaluation instruments from the point of view of their methodology, where feasible, appears to be the first possible solution to the unsatisfactory use of CBA. Among others, an alternative instrument is cost-effectiveness analysis (CEA) or cost-utility analysis (CUA), or other methods, such as discussed in [28]. CEA can be applied where a clear political goal is declared that can be reflected by a single measure of effectiveness and only the most effective path towards this goal is sought [18]. CEA enables to choose projects that generate the greatest effect per dollar spent. CUA is a close relative to CEA. It works with the preferences of individuals and seeks to choose a project, from which highest satisfaction of individuals per dollar spent is gained. This satisfaction is called utility. CUA works with a single measure or multiple measures of effectiveness [18]. Similarly to CEA, the outcomes of alternatives are not necessarily expressed in monetary terms in CUA.

CEA and CUA are widely used in healthcare [24] or education [18]. These areas are characterised by a very difficult expression of non-monetary effects in monetary terms. There is no reason why CEA or CUA could not be applied more frequently in other areas too, such as projects' selection for EU funding, for instance in environmental protection area. Air pollution may be taken as an example of an area which may profit from the use of these methods. Pollution limits for substances such as PM10 (fine dust particles in the air) are exceeded in many regions and their reduction can be part of policy objectives defined in Operational Programmes for EU funding. When a policy objective is set, the most costeffective way towards its fulfilment is sought. Measures reducing the emissions of PM10 to the air frequently have additional outcomes too, such as a reduction in the emissions of sulphur dioxide and greenhouse gases. CEA would not take these side effects into account. CUA would take them into consideration by the assignment of specific weights to different pollutants. Neither CEA nor CUA are problem-free in their practical applications however. [17] bring ex-post evaluation of twenty four CE studies of cancer therapies and find considerable methodological flaws in a significant number of them. Similarly, [11] critically appraised fifty-four CU studies in child health with a similar conclusion.
Alternative methods cannot be applied to projects that are original by nature and whose necessity is not clearly defined by a political decision. CBA may appear as the only suitable criterion for decisions particularly in such cases. However, CBA results have to be trusted then. The results will only be trustworthy if the author's professionalism and interest in performing CBA impartial can be relied upon. CBA performers must not be answerable to EU funding applicants to decrease the bias. The chain of players for the CBA elaboration for obtaining subsidies from EU Funds needs to be changed accordingly to enable an unbiased review of the project by CBA. Therefore we propose the following mechanism:

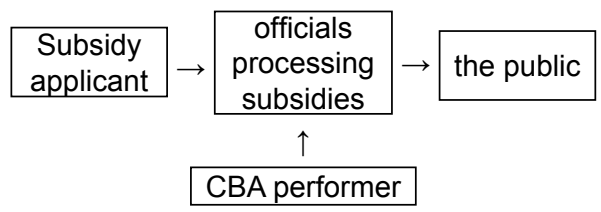

The reliability of the analyses will also be supported by the strict publication of the full CBA procedures that will enable an expert discussion of the CBA methodology and inputs, thus a more effective control. The CBA procedure must not be a black box. The possibility of a more effective control may at least decrease the rate of the deliberate manipulation of the CBA results. The trustworthiness of CBA would be much helped if their performers were liable for clearly unprofessional CBA. This could be helped by publishing a kind of a blacklist of unprofessional CBA performers or certification of expert CBA performers if the certificate might be suspended or revoked upon the identification of clearly unprofessional CBA.

\section{Conclusion}

Generally speaking, there is an agreement among mainstream economists that in a certain form and circumstances, CBA is the best possible evaluation tool for public sector decision-making. CBA introduces a certain order to decisionmaking. The possibility of arguing based on its results improves the transparency of decisionmaking and allows more effective control over politicians' actions. Nonetheless, CBA faces considerable practical problems which may impose limitation on its use.

The paper deals with the question of trustworthiness of practical execution of CBA on 
an example of CBA performance. Our concerns relate to the interest in bending the CBA results for one's own benefit. We present results of the survey among performers of CBA for purposes of EU subsidy applications. We examine the situation of the Czech Republic.

The person choosing the CBA performer for the purposes of project appraisal for EU funding is at the same time the subsidy applicant and thus with a clear interest in the optimistic result of the CBA. As our survey among commercial CBA performers shows, many entities performing CBA lack expert background for CBA performance and performed CBA are often biased and misleading. CBA performers are not required to obtain any certificates before performing CBA, meaning virtually anyone is free to offer CBA performance on the market. Another reason for inexpert CBA outcomes is the fact that the complicated CBA methodology prohibits a good awareness of it among the public, officials and politicians, rendering the effective review of CBA outcomes difficult. The relevance of the CBA results is questionable in such an environment.

Some conclusions and recommendations can be drawn from the above. Less demanding methods, such as CEA or CUA can be employed in decision-making instead of CBA, if feasible. We may wish to use CBA if other analyses cannot be applied in the given case. However, CBA results have to be trustworthy. The trustworthiness of CBA would be much helped if its performer was not answerable with the CBA result to the EU subsidy applicant and was liable for any unprofessional CBA. CBA performance makes sense only if we can rely on its results.

The author is grateful to Ondřej Vojáček, Ph.D. for his valuable comments. Thanks go also to my student Pavla Murgašová for her assistance in collecting data from commercial CBA performers in the Czech Republic.

\section{References}

[1] ADLER, M.D. and POSNER, E. Rethinking Cost-Benefit Analysis. Yale Law Journal. 1999, Vol. 109, Iss. 2, pp. 165-247. ISSN 0044-0094. DOI: $10.2307 / 797489$.

[2] ALMANSA, C. and MARTÍNEZ-PAZ, J.M. What weight should be assigned to future environmental impacts? A probabilistic cost benefit analysis using recent advances on discounting. Science of the Total Environment. 2011, Vol. 409, Iss. 7, pp. 1305-1314. ISSN 00489697. DOI: 10.1016/j.scitotenv.2010.12.004.

[3] ARROW, K.J. Social Choice and Individual Values. New York: Wiley, 1951. ISBN 0300013647.

[4] BEDNAŘíKOVÁ, Z. and JíLKOVÁ, J. Why is the Agricultural Lobby in the European Union Member States so Effective? E+M Ekonomie a Management. 2012, Vol. 15, Iss. 2, pp. 26-37. ISSN 1212-3609.

[5] COLETTI, P. and RADAELLI, C.M. Economic Rationales, Learning, and Regulatory Policy Instruments. Public Administration. 2013, Vol. 91, Iss. 4, pp. 1056-1070. ISSN 1467-9299. DOI: 10.1111/padm. 12006.

[6] DRYZEK, J.S. The Politics of the Earth: Environmental Discourses. Oxford: Oxford University Press, 2005. ISBN 0-19-927739-7.

[7] FOGLIA, A.T. and JENNINGS, A.K. A Happiness Approach to Cost-Benefit Analysis. Duke Law Journal. 2013, Vol. 62, Iss. 8, pp. 1503-1508. ISSN 0012-7086.

[8] FRANK, R.H. Why is Cost-Benefit Analysis so Controversial? In: HAUSMAN, D.M. (Ed.). The Philosophy of Economics, An Anthology. 3rd ed. New York: Cambridge University Press, 2008. pp. 251-269. ISBN 0-521-88350-4.

[9] GARROD, G. and WILLIS, K.G. Economic Valuation of the Environment, Methods and Case Studies. Edward Elgar, 1999. ISBN 1-85898-684-2.

[10] GRAMLICH, E.M. A Guide to Cost-Benefit Analysis. London: Prentice-Hall, 1990. ISBN 0881339881.

[11] GRIEBSCH, I., COAST, J. and BROWN, J. Quality-Adjusted Life-Years Lack Quality in Pediatric Care: A Critical Review of Published Cost-Utility Studies in Child Health. Pediatrics. 2005, Vol. 115, Iss. 5, pp. 600-614. ISSN 00314005. DOI: 10.1542/peds.2004-2127.

[12] HANLEY, N., SHOGREN, J.F. and WHITE, B. Environmental Economics in Theory and Practice. 2nd ed. Palgrave Macmillan, 2007. ISBN 0-333-97137-x.

[13] HANLEY, N. and SPASH, C.L. Cost-Benefit Analysis and the Environment. Aldershot: Edward Elgar, 1995. ISBN 1-85278-455-5.

[14] HARRISON, M. Valuing the Future: The Social Discount Rate in Cost-Benefit Analysis. Visiting Researcher Paper. Canberra: Productivity Commission, 2010.

[15] HYARD, A. Cost-benefit analysis according to Sen: An application in the 
evaluation of transport infrastructures in France. Transportation Research Part A: Policy and Practice. 2012, Vol. 46, Iss. 4, pp. 707-719. ISSN 0965-8564. DOI: 10.1016/j. tra.2012.01.002.

[16] KOTÍKOVÁ, E. Ochrana životního prostředí v ekonomické teorii. Politická ekonomie. 2006, Vol. 54, Iss. 2, pp. 261-273. ISSN 0032-3233. DOI: $10.18267 /$ j.polek.557.

[17] LEUNG, H.W., et al. Systematic Review and Quality Assessment of Cost-Effectiveness Analysis of Pharmaceutical Therapies for Advanced Colorectal Cancer. The Annals of Pharmacotherapy. 2013, Vol. 47, Iss. 4, pp. 506518. ISSN 1060-0280. DOI: 10.1345/aph.1R152. [18] LEVIN, H.M. and McEWAN, P.J. CostEffectiveness Analysis. 2nd ed. Thousand Oaks, CA: Sage Publications, 2001. ISBN 0761919341.

[19] MANDELL, S. Carbon emission values in cost benefit analyses. Transport Policy. 2011, Vol. 18, Iss. 6, pp. 888-892. ISSN 0967-070X. DOI: 10.1016/j.tranpol.2011.06.005.

[20] MOUTER, N., ANNEMA, J.A. and VAN WEE, B. Ranking the substantive problems in the Dutch Cost-Benefit Analysis practice. Transportation Research Part A: Policy and Practice. 2013, Vol. 49, pp. 241-255. ISSN 0965-8564. DOI: 10.1016/j.tra.2013.01.020.

[21] NORDHAUS, W.D. A Review of the Stern Review on the Economics of Climate Change. Journal of Economic Literature. 2007, Vol. 45, Iss. 3, pp. 686-702. ISSN 0022-0515. DOI: 10.1257/jel.45.3.686.

[22] PORTNEY, P. and WEYANT, J. Introduction. In: PORTNEY, P. and WEYANT, J. (Eds.). Discounting and Intergenerational Equity. Resources for the Future Press, 1999. pp. 1-11. ISBN 0915707896.

[23] RADAELLI, C.M. Measuring Policy Learning: Regulatory Impact Assessment in Europe. Journal of European Public Policy.
2009, Vol. 16, Iss. 8, pp. 1145-1164. ISSN 13501763. DOI: $10.1080 / 13501760903332647$.

[24] RUSSELL, L.B., et al. The Role of Costeffectiveness Analysis in Health and Medicine. JAMA, The Journal of the American Medical Association. 1996, Vol. 276, Iss. 14, pp. 1172-1177. ISSN 1538-3598. DOI: 10.1001/ jama.1996.03540140060028.

[25] SEN, A. The Discipline of Cost-Benefit Analysis. The Journal of Legal Studies. 2000, Vol. 29, Iss. S2, pp. 931-952. ISSN 1744-1722. DOI: $10.1086 / 468100$.

[26] SLAVÍKOVÁ, L., VEJCHODSKÁ, E., SLAVÍK, J., et al. Ekonomie životního prostředí: teorie a politika. Praha: Alfa, 2012. ISBN 97880-87197-45-5.

[27] STERN, N. The Economics of Climate Change, The Stern Review. Cambridge University Press, 2007. ISBN 9780521700801. [28] ŠAUER, P., et al. Assessment of Environmental Policy Implementation: Two Case Studies from the Czech Republic. Polish Journal of Environmental Studies. 2012, Vol. 21, Iss. 5, pp. 1383-1391. ISSN 1230-1485.

[29] VINING, A. and WEIMER, D.L. An assessment of important issues concerning the application of benefit-cost analysis to social policy. Journal of Benefit-Cost Analysis. 2010, Vol. 1, Iss. 1. ISSN 2152-2812. DOI: 10.2202/2152-2812.1013.

[30] VOJÁČEK, O. and PECÁKOVÁ, I. Comparison of Discrete Choice Models for Economic Environmental Research. Prague Economic Papers. 2010, Vol. 19, Iss. 1, pp. 35-53. ISSN 1210-0455. DOI: 10.18267/j.pep.363.

Ing. Eliška Vejchodská, Ph.D. Jan Evangelista Purkyně University in Ústí nad Labem

Faculty of Social and Economic Studies VYCERRO eliska.vejchodska@seznam.cz 


\section{Abstract}

\section{COST-BENEFIT ANALYSIS: TOO OFTEN BIASED}

\section{Eliška Vejchodská}

Cost-benefit analysis (CBA) is widely applied in many countries in evaluating public projects and regulatory instruments. It is employed, for example, as a basis for decisions within the European Union's subsidy policy. CBA enables to express the comprehensive effect of a project or a governmental regulation on social welfare and thereby to introduce expertise to political decision-making. However, its practical applications face many problems. Different methodological choices in performing CBA enable to obtain diametrically opposite conclusions. Moreover, the way how investors apply for EU Fund subsidies encourages CBA performers to adjust CBA results to requirements of subsidy applicants. The unavoidable consequence is frequently mendacious, unreliable and misleading CBA. The paper brings an overview of the flexibility in CBA methodological choices. It further focuses on analysing the CBA performance practice in the area of CBA project appraisal for the purposes of applying for EU funding. We examine the reasons for manipulating results using a theoretical analysis and support our findings by our own empirical survey among CBA performers. As our survey among commercial CBA performers uncovers, many entities performing CBA lack expert background for CBA performance and performed CBA are often biased and misleading. Our theoretical analysis shows its main reason: The person choosing and remunerating the CBA performer for the purposes of a project appraisal for EU funding is at the same time the subsidy applicant and thus with a clear interest in the optimistic result of the CBA. CBA performers are happy to oblige their customers. The remedy to this situation is to get rid of this unintentional alliance among CBA performers and subsidy applicants.

Key Words: Cost-benefit analysis, CBA, bias, reflection, Czech Republic.

JEL Classification: D61, Q38.

DOI: 10.15240/tul/001/2015-4-005 